\title{
HS and Inflammation: A Potential Playground for the Sulfs?
}

\author{
Rana El Masri, Yoann Crétinon, Evelyne Gout and Romain R. Vivès* \\ Université Grenoble Alpes, CNRS, CEA, Institut de Biologie Structurale (IBS), Grenoble, France
}

Heparan sulfate (HS) is a complex polysaccharide abundantly found in extracellular matrices and cell surfaces. HS participates in major cellular processes, through its ability to bind and modulate a wide array of signaling proteins. HS/ligand interactions involve saccharide domains of specific sulfation pattern. Assembly of such domains is orchestrated by a complex biosynthesis machinery and their structure is further regulated at the cell surface by post-synthetic modifying enzymes. Amongst them, extracellular sulfatases of the Sulf family catalyze the selective removal of 6-O-sulfate groups, which

OPEN ACCESS

Edited by:

Rogier M. Reijmers,

Leiden University Medical

Center, Netherlands

Reviewed by:

Kenji Uchimura,

UMR8576 Unité de Glycobiologie Structurale et Fonctionnelle, France

Mark Michael Fuster,

University of California, San Diego,

United States

Steven David Rosen,

University of California,

San Francisco, United States

*Correspondence:

Romain R. Vivès

romain.vives@ibs.fr

Specialty section:

This article was submitted to

Inflammation,

a section of the journal

Frontiers in Immunology

Received: 04 December 2019

Accepted: 12 March 2020

Published: 03 April 2020

Citation:

El Masri R, Crétinon Y, Gout E and Vivès RR (2020) HS and Inflammation: A Potential Playground for the Sulfs?

Front. Immunol. 11:570

doi: 10.3389/fimmu.2020.00570 participate in the binding of many proteins. As such, increasing interest arose on the regulation of HS biological properties by the Sulfs. However, studies of the Sulfs have so far been essentially restricted to the fields of development and tumor progression. The aim of this review is to survey recent data of the literature on the still poorly documented role of the Sulfs during inflammation, and to widen the perspectives for the study of this intriguing regulatory mechanism toward new physiopathological processes.

Keywords: heparan sulfate (HS), inflammation, glycosaminoglycan/protein interactions, sulfatase, chemokine, leukocyte migration

\section{INTRODUCTION}

Heparan sulfate proteoglycans (HSPGs) are major components of the cell surface, extracellular matrix (ECM) and basement membrane in most animal cells. They are composed of a protein core, onto which are covalently attached complex, anionic Heparan Sulfate (HS) chains of the glycosaminoglycan (GAG) polysaccharide family. Through the ability of their HS chains to bind, modulate and control bioavailability of a multitude of protein ligands, HSPGs are involved in a plethora of biological processes, including cell adhesion, migration, proliferation and differentiation, embryo development, inflammation, control of angiogenesis, blood coagulation, tumor growth, and metastasis (1-3). Structurally, a HS chain is characterized by the linear repetition of a disaccharide unit, composed of alternating $\mathrm{N}$-acetyl glucosamine (GlcNAc) and glucuronic acid (GlcA). During biosynthesis, the polymer undergoes a series of modifications, which include the $\mathrm{N}$-deacetylation/ $\mathrm{N}$-sulfation of glucosamine to form $\mathrm{N}$-sulfo glucosamine (GlcNS), the C5 epimerization of GlcA into iduronic acid (IdoA), and $\mathrm{O}$-sulfations at positions $\mathrm{C} 2$ of IdoA and C6 (more rarely C3) of glucosamine residues. Tight regulation of these modification steps leads to the generation of specialized saccharide regions termed S-domains, exhibiting both remarkable structural diversity and high sulfation content. These S-domains are involved in the recognition and binding of most HS ligands (4-6). HS is structurally closely related to heparin, although the latter displays a much higher sulfation content. Therefore, heparin has been widely used as a surrogate of HS S-domains for protein interaction studies. 


\section{HS IN INFLAMMATION}

Inflammation is a complex, multi-step process leading to the rapid recruitment of leukocytes from the blood to the inflammation site. Briefly, emission of an inflammatory signal triggers the secretion of cytokines and chemokines that diffuse throughout the tissue and activate leukocytes and vascular endothelial cells. Cell activation leads to the adhesion and rolling of leukocytes on the endothelium toward the inflammatory site. Leukocytes will then cross the endothelium to the basement membrane, and migrate toward the inflamed tissue to initiate immune responses. Through its large protein binding properties, HS participates in various steps of inflammation [for review, see $(7,8)]$.

Inflammation is first initiated by the production, upon endogenous or exogenous signals, of inflammatory cytokines. Amongst these, chemokines are a family of small proteins involved in many biological processes such as development, inflammation and immunosurveillance (9). Chemokines induce the activation of the endothelium and the migration of leukocytes from blood toward inflammatory sites. To elicit their functions, they bind to their primary G-coupled receptors that trigger downstream signaling. In addition, all chemokines bind to cell surface and ECM HS. The structural basis of these interactions has been intensively studied and is now well documented (10-12).

Functionally, HS does not seem to be essential for chemokine signaling in vitro. However, in vivo studies showed that chemokines unable to bind to HS failed to recruit leukocytes (13), and that HS modulated chemokine activity through different mechanisms [for review, see $(12,14)$ ]. HS first regulates chemokine diffusion and sequestration. In some instance, the capture of the chemokine/cytokine by HS prevents its release and thus its activity (15). However, by regulating chemokine diffusion, HS participates in the formation and stabilization of chemotactic gradients providing directional cues for migrating leukocytes. In support to this, in vivo inhibition of CXCL12/HS interaction using sulfated polysaccharide tilted the chemokine distribution from bone marrow toward the plasma, thereby causing the release of hematopoietic progenitor cells in the blood circulation (16). HS also mediates chemokine transcytosis across the endothelial cell wall $(17,18)$, and protects chemokines/cytokines from enzymatic degradation and inactivation (19-21). Finally, HS may further modulate chemokine activity by inducing chemokine oligomerization [for review, see (11)], which has been shown to be functionally relevant in vivo (13). In that context, an original HS-dependent cooperative mechanism driving CCL5 dimerization has been characterized (22).

Activation by pro-inflammatory chemokines and cytokines induces the expression of endothelial C-type lectins E- and Pselectins. These bind a variety of glycosylated ligands present on the leukocyte cell surface to initiate adhesion and rolling of leukocytes on the endothelium. Recruitment is further promoted through additional interactions, involving L-selectin constitutively expressed on leukocytes with leukocyte and endothelial ligands $(23,24)$. HS may participate to this process, as studies reported binding to L-selectin $(24,25)$, P-selectin (26), and E-selectin $(27,28)$. However, it should be noted that the physiological relevance of these interactions remains to be clarified. Studies showed that the removal of cell surface HS with heparinases reduced L-selectin dependent binding of monocytes, and leukocyte rolling on endothelial cells $(29,30)$. During acute inflammation, HS was shown to support L-selectin dependent rolling of neutrophils on lung microvasculature (31). On the contrary, lymphocyte rolling on high endothelial venules (HEV) exclusively relied on interactions of $\mathrm{L}$-selectin with ligands bearing sialyl Lewis $\mathrm{X}\left(\mathrm{sLe}^{\mathrm{X}}\right)$ glycosylation motifs, suggesting no involvement of HS in L-selectin-dependent lymphocyte homing (32). One could speculate that these discrepancies could be due to the presence of distinct HS structures and/or sLe $\mathrm{S}^{\mathrm{x}}$ ligands on these different cell types.

Leukocyte rolling is then arrested through increased integrinmediated cell-cell adhesion. In a recent study, it has been proposed that endothelial cell surface HS could participate indirectly to this process, by capturing and presenting CCL21, which would in turn activate integrin LFA-1 on rolling lymphocytes (32). Following arrest, leukocytes get access to inflamed tissues through extravasation across the endothelial cell wall. They then reach the basement membrane that comprises numerous interacting molecules and a variety of HSPGs, including perlecan, agrin and XVIII collagen, which may further modulate the extravasation process. These HSPGs can bind many chemokines, cytokines and growth factors that are critical for leukocyte migration, and contribute to the formation of chemokine gradients. On the contrary, they can act as a physical barrier hindering leukocyte migration.

Finally, studies have also suggested a role of HS in the phagocytosis process $(33,34)$. A proposed mechanism is that newly-exposed HS binding sites at the surface of apoptotic cells could facilitate their recognition, uptake and clearance by macrophages (35). However, in vivo data are still needed to clarify this process.

Most of these inflammatory steps are generally accompanied by changes in the expression of their cell-surface HPSGs and HS structure. Many studies have reported an upregulation of cellsurface HSPG Syndecan-1 upon endothelial cell activation by pro-inflammatory cytokines [reviewed in (25)]. Differentiation of monocytes into macrophages leads to high expression of Syndecan-1, -2 and -4 , whereas macrophage activation by Interleukin (IL)-1 results in the overexpression of Syndecan-2 only (36). Furthermore, the activation of $\mathrm{T}$ cells induces the expression of Syndecans and Glypicans, while the differentiation of B cells into plasma cells specifically triggers Syndecan-1 expression $(37,38)$. Depending on the inflammatory stimuli, HS length, structure and sulfation profiles may also be affected. For instance, the size and 6-O-sulfation patterns of HS are altered in primary human endothelial cells upon treatment with tumor necrosis factor (TNF $\alpha$ ) or IL-1 (39). Pro-inflammatory effectors have been shown to modulate the expression of NDSTs (4042). In particular induction of NDST1 led to the production of highly sulfated HS that increased the sequestration of CCL5, thereby promoting leukocyte extravasation (42). Vascular lesions in mice have also been associated with a significant increase 
of NDST1 expression (43). In line with this, inactivation of NDSTs in endothelial cells led to impaired rolling and infiltration of neutrophils and macrophages into inflammatory sites $(31,44)$. In contrast, restricted inactivation of NDSTs to leukocytes had no effect on leukocyte infiltration (31). Changes in HS $\mathrm{O}$-sulfotransferases (OSTs) expression have also been reported, during macrophage M1/M2 polarization (45), or the development of renal fibrosis (46). Interestingly, the stimulation of human monocytes by LPS or TNFa upregulates only one out of the seven 3OST isoform: 3OST3b, thus highlighting the fine tuning of sulfotransferase expression pattern during inflammation (47). Finally, the silencing of 2OST in mouse endothelial cells during acute inflammation resulted in enhanced HS 6-O- and $\mathrm{N}$-sulfation, leading to increased neutrophil infiltration (48).

\section{POST-EDITING MECHANISMS REGULATING HS DISTRIBUTION, STRUCTURE AND FUNCTION}

Although HS expression and structure is primarily controlled during polysaccharide biosynthesis, increasing evidence have also highlighted the importance of the additional regulatory step provided by post-editing enzymes, including Heparanase, sheddases, and sulfatases of the Sulfs family.

In inflammatory processes, post-synthesis regulation of HS plays a significant role. Heparanase is an endo- $\beta-D-$ glucuronidase targeting [GlcA-GlcNS] linkages within HS. Heparanase cleaves long HS chains from ECM and cell-surface HSPGs into shorter fragments of 10-20 sugar units. This results in the release of sequestered HS bound ligands, such as growth factors, chemokines and morphogens, which can then induce angiogenesis, cell proliferation and motility (49). Consequently, Heparanase has been associated with various pathologies, including cancer, inflammation, thrombosis, atherosclerosis, fibrosis, diabetes, and kidney disease (50). During inflammation, Heparanase plays multiple roles. It favors neutrophil adhesion onto the endothelium, by degrading endothelial cell-surface HS and unmasking membrane adhesion molecules (51). It also facilitates leukocyte extravasation, by degrading basement membrane HSPGs (52). More recently, Heparanase has been shown to enhance T-cell activity (53). Furthermore, intracellular heparanase upregulated the transcription of genes involved in T-cell differentiation (54). Finally and noteworthy, Heparanase expression is also markedly increased during neuroinflammation (55).

Shedding of HSPGs takes place upon activation of metalloproteinases, plasmins and elatases by inflammatory cytokines (56-59). These proteases target the core protein of HSPGs like Syndecans, thus releasing soluble HS-peptide conjugates. Shedding regulates the amount of HSPGs found at the cell surface or in the ECM and facilitate the release of sequestered chemokines, which contributes to the resolution of neutrophilic inflammation $(58,60)$. In combination with Heparanase, shedding also facilitate leukocyte migration by altering the architecture of the ECM and basement membranes (52).

In addition, soluble released HS fragments/conjugates (produced by sheddases or Heparanase) induce the secretion by macrophages and splenocytes of pro-inflammatory cytokines through activation of the NF- $\kappa$ B signaling pathway (61-63). Soluble HS fragments also activate neutrophils and promote an immune response via toll like receptor-4 $(64,65)$. They can also trigger the maturation of dendritic cells, leading to their migration toward lymphoid organs to elicit primary immune responses (66). In line with this, it was shown that an exogenous administration of HS or elastase resulted in a systemic inflammatory response syndrome (SIRS)-like reaction (67).

\section{THE SULFS: POST-SYNTHETIC REGULATORS OF HS STRUCTURE AND FUNCTION}

Sulfs are extracellular endosulfatases that catalyze the 6-Odesulfation of HS. Sulf-1 was first discovered in Quail (68), then orthologs were later identified in mouse, rat, chick, $C$. elegans, zebrafish, and human, as well as a second related enzyme, Sulf-2 (69). In human, HSulf-1 and HSulf-2 (encoded by two distinct genes) feature a common structural organization (69). Maturation of the sulfs involves furin-type processing of proenzyme proteins, yielding two sub-units linked by one or more disulfide bonds (see Figure 1 inset). The $\mathrm{N}$-terminal regions features the enzyme catalytic (CAT) domain, which shows strong homology with most eukaryotic sulfatases. The CAT domain comprises the enzyme active site, including the two conserved sulfatase signature amino acid sequences as well as the cysteine modified, catalytic FGly residue. The second functional domain of the Sulfs is the highly charged basic domain (HD), which spans over both $\mathrm{N}$-terminal and C-terminal sub-units. The HD domain is a unique feature of the Sulfs, as it shares no homology with any other known protein. It is responsible for high affinity binding to HS substrate and is therefore required for the enzyme endo-6-O-sulfatase activity (70-73). In addition, the HD domain has been shown to mediate the capture of Sulfs on cell-surface HS thereby modulating enzyme diffusion (71). Finally, Sulf Cterminal region shows homology to Glucosamine-6-sulfatase (G6S) and Arabidopsis thaliana GlcNAc transferase, suggesting a role of this domain in the recognition of glucosamine motifs (69).

Sulfs catalyze the 6-O-desulfation of $\mathrm{HS}$ with a strong preference for [Glc/IdoA(2S)-GlcNS(6S)] trisulfated disaccharides that are essentially found within S-domains. Although abundant in heparin, this disaccharide motif is relatively scarce in HS. Sulf-induced modification of HS structure is therefore structurally subtle, but with great functional consequences, as 6-O-sulfation pattern of HS Sdomains is critical for the binding of many signaling proteins (74). Sulfs are therefore implicated in a number of physiological and pathological processes, including development, tissue repair, neurodegenerative disease and cancer [for reviews, see (75-77)]. 


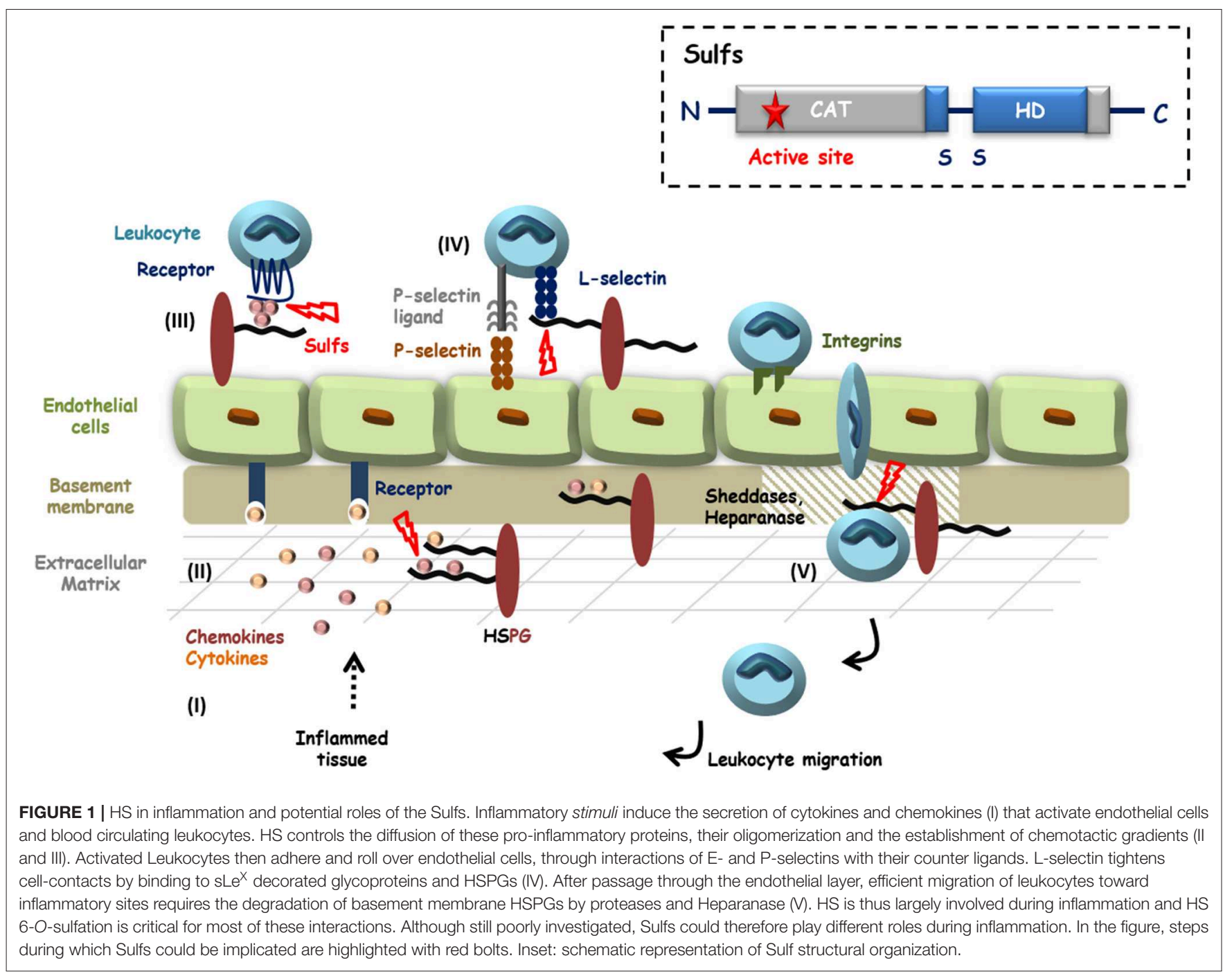

\section{DISCUSSION: POTENTIAL ROLES OF THE SULFS DURING INFLAMMATION}

Over the recent years, Sulfs have emerged as critical regulators of HS functions, with well documented roles during development and cancer. However and despite growing evidence, Sulfs have remained largely unstudied in the context of inflammation (see Figure 1).

It is first well established that $\mathrm{HS}$ 6-O-sulfation is a major structural determinant for the interaction with many chemokines, including CXCL12 (78-80), CXCL8 (81, 82), CXCL4 $(83,84)$ and CCL5 (85). For the latter, the resolution of the CCL5 crystal structure in complex with heparin provided further evidence of the contribution of 6-O-S group in the interaction (85). Furthermore, HS mimetic glycopolymers featuring [IdoA(2S), GlcNS(6S)] disaccharides efficiently inhibited CCL5/heparin interaction (86). In this context, it is therefore most likely that Sulfs would significantly affect HS binding properties toward many of these chemokines, with consequences on chemokine oligomerization, storage, bioavailability and diffusion. Interestingly, a recent study investigating chemokine inhibition using synthetic sulfated $[\operatorname{IdoA}(2 \mathrm{~S}), \mathrm{GlcNS}( \pm 6 \mathrm{~S})]_{6}$ dodecasaccharides showed that the presence of a 6-O-sulfate group on the non-reducing end residue switched saccharide binding properties from CXCL8 toward CXCL12 (87). In light of this, it was also recently reported that HSulfs catalyzed the 6-O-desulfation of HS following a processive and orientated mechanism, starting from S-domain non-reducing end (88). Together, these data thus suggest that Sulfs could tune HS binding selectivity for chemokines. Despite these findings and most surprisingly, the effect of Sulfs on $\mathrm{HS} /$ chemokine interaction has so far only been investigated in one study, which showed the inhibition of CXCL12- $\alpha$ binding to heparin by the Sulfs in an in vitro immunoassay (79).

Studies have reported that the 6-O-sulfation of endothelial HS was critical for leukocyte rolling (89), and that 6-Osulfation of heparin was necessary to block L-selectin mediated leukocyte adhesion $(80,90)$. Sulfs could thus be involved in the 
control of leukocyte adhesion and migration on the activated endothelium. Vascular glycocalyx and especially endothelial HS undergo significant degradation during inflammation (91). A role of the Sulfs in these mechanisms could thus be postulated, as suggested by a first study on post-septic mice. Sepsis is associated with a hyper-inflammatory process, followed by a delayed period of immunosuppression called compensatory anti-inflammatory response syndrome (CARS), which can lead to secondary infections. This study showed that HS of lung endothelial glycocalyx displayed higher 6-O-sulfation content after septic injury, which was due to a downregulation of Sulf1. Interestingly, the post-septic loss of Sulf-1 was necessary for CARS to occur, as the administration of exogenous recombinant Sulf-1 intravenously reversed the immunosuppression phenotype (92). In the same context, Sulfs could also participate in the degradation of the basement membrane, along with Heparanase and proteases to facilitate leukocyte migration toward inflammatory sites. Although there is no evidence of such an involvement yet, a study preceding the discovery of the Sulfs showed that activation of endothelial cells with pro-inflammatory cytokines led to the detection of a sulfatase activity, which was required for the degradation of the basement membrane (52).

Changes in the expression of the Sulfs upon inflammatory conditions have been reported. An in vivo study on renal allograft biopsies showed that Sulf-1 expression was repressed in inflammatory conditions (93). In contrast, HSulf-1 was upregulated in human fibroblasts upon TNF- $\alpha$ treatment (94). Likewise, TGF- $\beta 1$ induced the expression of Sulf- 2 in renal epithelial cells (95), and of both Sulf-1 and Sulf-2 in lung fibroblasts (96). In line with this, Sulf-2 was overexpressed in idiopathic pulmonary fibrosis (97) and would act as a regulator, in a negative feedback loop, of TGF- $\beta 1$ signaling in type 2 alveolar epithelial cells $(96,97)$. Furthermore, it was shown that Sulf-2 expression in type II alveolar epithelial cells played a protective role in epithelial lung injury, inflammation and mortality (98). Surprisingly, Sulf-2 overexpression in human hepatocellular carcinoma cells promoted TGF- $\beta 1$ signaling (99). Altogether, these data clearly underline the complex interplay between Sulf activities and TGF- $\beta 1$ signaling.

One still intriguing and yet poorly understood issue about the Sulfs is that the two human forms, HSulf-1 and HSulf-2, feature very similar enzyme activities in vitro, but show clear functional discrepancies in vivo. As such, a study on Sulf KO mice indicated that both forms exhibit redundant or overlapping functions during development $(100,101)$, while accumulating data describe opposite activities in cancer $(75,76)$. Furthermore, it has been reported that alternative splicing of Sulf1/Sulf2 genes generated functionally active variants. In Quail, a QSulf-1 variant (QSulf-1B) encoding for a shorter protein form exhibited opposite activities to full length QSulf-1, QSulf-1B inhibiting Wnt signaling and promoting angiogenesis (102). Mammalian variants of Sulf1 and Sulf2 were later identified in tumors (103, 104). The occurrence and biological significance of Sulf variants are still poorly understood. However, some of these variants have been shown to regulate growth factor signaling pathways and to display anti-oncogenic and anti-angiogenic properties (105). Noteworthy, the expression of Sulf-1 and Sulf-2 variants was also reported in the context of inflammation (105). Studying the spatial and temporal expression and activity of the two Sulf forms as well as their respective splice variants may therefore be critical to fully understand the role of these enzymes in a given biological process such as inflammation.

Finally, another interesting observation arose from our recent article reporting the expression and purification of recombinant HSulf-2 (73). In this work, we showed that the protein HD domain was very sensitive to proteolytic digestion. This observation is in agreement with secondary structure predictions based on amino-acid sequence, which suggests the presence of large unstructured regions within the HD domain. Most surprisingly, we found that these degraded forms of HSulf2 displayed endosulfatase activity. This is in agreement with a previous study, which demonstrated that deletion of the inner region of HSulf-1 HD domain did not abrogate enzyme activity (71). However, partial degradation of the HD domain may significantly affect HS substrate selectivity and/or the HDdependent immobilization of Sulfs on cell-surface HS (71). It could thus be hypothesized that, under inflammatory conditions, protease-driven processing of the HD could affect both Sulf biological activity and diffusion throughout tissues.

In conclusion, the structural and functional regulation of HS by the Sulfs is undeniably a significant topic of interest, which merits further investigation in the context of inflammation. Evidence of Sulf involvement in inflammatory processes and in the modulation of pro-inflammatory effectors are slowly arising, but progress in the field has been hampered by the complexity of these enzymes, which markedly distinguishes them from other eukaryotic sulfatases. Nevertheless, recent access to purified recombinant protein solved a critical technical bottleneck, which should boost progress in their study. In this context, we reported for the first time the intravenous injection of recombinant enzyme in vivo to analyze an inflammatory process (92), and we anticipate that this study will pave the way to further investigations in this field.

\section{AUTHOR CONTRIBUTIONS}

All authors listed have made a substantial, direct and intellectual contribution to the work, and approved it for publication.

\section{FUNDING}

The authors would like to acknowledge the support of Grenoble Instruct centre (ISBG; UMS 3518 CNRS-CEA-UJF-EMBL) with support from FRISBI (ANR-10-INSB-05-02) and GRAL (ANR-10-LABX-49-01) within the Grenoble Partnership for Structural Biology (PSB), of the GDR GAG (GDR 3739) and the Investissements d'avenir program Glyco@Alps (ANR-15-IDEX02), and of grants from the Agence Nationale de la Recherche (ANR-12-BSV8-0023 and ANR-17-CE11-0040) and Université Grenoble-Alpes (UGA AGIR program).

\section{ACKNOWLEDGMENTS}

The authors would like to thank Professor John Gallagher for his diligent proofreading of the manuscript. 


\section{REFERENCES}

1. Sarrazin S, Lamanna WC, Esko JD. Heparan sulfate proteoglycans. Cold Spring Harb Perspect Biol. (2011) 3:4952. doi: 10.1101/cshperspect.a004952

2. Iozzo RV, Schaefer L. Proteoglycan form and function: a comprehensive nomenclature of proteoglycans. Matrix Biol. (2015) 42:11-55. doi: 10.1016/j.matbio.2015.02.003

3. Kjellén L, Lindahl U. Specificity of glycosaminoglycan-protein interactions. Curr Opin Struct Biol. (2018) 50:101-8. doi: 10.1016/j.sbi.2017.12.011

4. Li J-P, Kusche-Gullberg M. Heparan sulfate: biosynthesis, structure, and function. Int Rev Cell Mol Biol. (2016) 325:215-73. doi: 10.1016/bs.ircmb.2016.02.009

5. Gallagher J. Fell-Muir lecture: heparan sulphate and the art of cell regulation: a polymer chain conducts the protein orchestra. Int J Exp Pathol. (2015) 96:203-31. doi: 10.1111/iep.12135

6. Lindahl U, Li JP. Interactions between heparan sulfate and proteins-design and functional implications. Int Rev Cell Mol Biol. (2009) 276:105-59. doi: 10.1016/S1937-6448(09)76003-4

7. Parish CR. The role of heparan sulphate in inflammation. Nat Rev Immunol. (2006) 6:633-43. doi: 10.1038/nri1918

8. Collins LE, Troeberg L. Heparan sulfate as a regulator of inflammation and immunity. J Leukoc Biol. (2019) 105:81-92. doi: 10.1002/JLB.3RU0618-246R

9. Zlotnik A, Yoshie O. The chemokine superfamily revisited. Immunity. (2012) 36:705-16. doi: 10.1016/j.immuni.2012.05.008

10. Lortat-Jacob H, Grosdidier A, Imberty A. Structural diversity of heparan sulfate binding domains in chemokines. Proc Natl Acad Sci USA. (2002) 99:1229-34. doi: 10.1073/pnas.032497699

11. Salanga CL, Handel TM. Chemokine oligomerization and interactions with receptors and glycosaminoglycans: the role of structural dynamics in function. Exp Cell Res. (2011) 317:590-601. doi: 10.1016/j.yexcr.2011.01.004

12. Monneau Y, Arenzana-Seisdedos F, Lortat-Jacob H. The sweet spot: how GAGs help chemokines guide migrating cells. J Leukoc Biol. (2016) 99:93553. doi: 10.1189/jlb.3MR0915-440R

13. Proudfoot AE, Handel TM, Johnson Z, Lau EK, LiWang P, Clark-Lewis I, et al. Glycosaminoglycan binding and oligomerization are essential for the in vivo activity of certain chemokines. Proc Natl Acad Sci U A. (2003) 100:1885-90. doi: 10.1073/pnas.0334864100

14. Proudfoot AE. The biological relevance of chemokine-proteoglycan interactions. Biochem Soc Trans. (2006) 34:422-6. doi: 10.1042/BST0340422

15. Miller JD, Clabaugh SE, Smith DR, Stevens RB, Wrenshall LE. Interleukin-2 is present in human blood vessels and released in biologically active form by heparanase. Immunol Cell Biol. (2012) 90:159-67. doi: 10.1038/icb.2011.45

16. Sweeney EA, Lortat-Jacob H, Priestley GV, Nakamoto B, Papayannopoulou T. Sulfated polysaccharides increase plasma levels of SDF-1 in monkeys and mice: involvement in mobilization of stem/progenitor cells. Blood. (2002) 99:44-51. doi: 10.1182/blood.V99.1.44

17. Middleton J, Neil S, Wintle J, Clark-Lewis I, Moore H, Lam C, et al. Transcytosis and surface presentation of IL- 8 by venular endothelial cells. Cell. (1997) 91:385-95. doi: 10.1016/S0092-8674(00)80422-5

18. Middleton J, Patterson AM, Gardner L, Schmutz C, Ashton BA. Leukocyte extravasation: chemokine transport and presentation by the endothelium. Blood. (2002) 100:3853-60. doi: 10.1182/blood.V100.12.3853

19. Sadir R, Imberty A, Baleux F, Lortat-Jacob H. Heparan sulfate/heparin oligosccharides protect stromal cell-derived factor-1 (SDF-1)/CXCL12 against proteolysis induced by CD26/dipeptidyl peptidase IV. J Biol Chem. (2004) 279:43854-60. doi: 10.1074/jbc.M405392200

20. Lortat-Jacob H, Baltzer F, Grimaud JA. Heparin decreases the blood clearance of interferon-gamma and increases its activity by limiting the processing of its carboxyl-terminal sequence. J Biol Chem. (1996) 271:1613943. doi: $10.1074 /$ jbc.271.27.16139

21. Jayanthi S, Koppolu BP, Nguyen KG, Smith SG, Felber BK, Kumar TKS, et al. Modulation of interleukin-12 activity in the presence of heparin. Sci Rep. (2017) 7:5360. doi: 10.1038/s41598-017-05382-1

22. Vives RR, Sadir R, Imberty A, Rencurosi A, Lortat-Jacob H. A kinetics and modeling study of RANTES(9-68) binding to heparin reveals a mechanism of cooperative oligomerization. Biochemistry. (2002) 41:1477989. doi: 10.1021/bi026459i
23. Rosen SD. Ligands for l-selectin: homing, inflammation, and beyond. Annu Rev Immunol. (2004) 22:129-56. doi: 10.1146/annurev.immunol.21.090501.080131

24. Ivetic A, Hoskins Green HL, Hart SJ. L-selectin: a Major regulator of leukocyte adhesion, migration and signaling. Front Immunol. (2019) 10:1068. doi: 10.3389/fimmu.2019.01068

25. Gotte M. Syndecans in inflammation. Faseb J. (2003) 17:575-91. doi: 10.1096/fj.02-0739rev

26. Nelson RM, Cecconi O, Roberts WG, Aruffo A, Linhardt RJ, Bevilacqua MP. Heparin oligosaccharides bind $1-$ and p-selectin and inhibit acute inflammation. Blood. (1993) 82:3253-58. doi: 10.1182/blood.V82.11.3253.3253

27. Koenig A, Norgard-Sumnicht K, Linhardt R, Varki A. Differential interactions of heparin and heparan sulfate glycosaminoglycans with the selectins. Implications for the use of unfractionated and low molecular weight heparins as therapeutic agents. J Clin Invest. (1998) 101:877-89. doi: 10.1172/JCI1509

28. Luo J, Kato M, Wang H, Bernfield M, Bischoff J. Heparan sulfate and chondroitin sulfate proteoglycans inhibit e-selectin binding to endothelial cells. J Cell Biochem. (2001) 80:522-31. doi: 10.1002/10974644(20010315)80:4<522::AID-JCB1006>3.0.CO;2-H

29. Giuffrè L, Cordey AS, Monai N, Tardy Y, Schapira M, Spertini O. Monocyte adhesion to activated aortic endothelium: role of 1-selectin and heparan sulfate proteoglycans. J Cell Biol. (1997) 136:945-56. doi: $10.1083 /$ jcb.136.4.945

30. Rops AL, Jacobs CW, Linssen PC, Boezeman JB, Lensen JF, Wijnhoven TJ, et al. Heparan sulfate on activated glomerular endothelial cells and exogenous heparinoids influence the rolling and adhesion of leucocytes. Nephrol Dial Transplant Off Publ Eur Dial Transpl Assoc - Eur Ren Assoc. (2007) 22:1070-7. doi: 10.1093/ndt/gfl801

31. Wang L, Fuster M, Sriramarao P, Esko JD. Endothelial heparan sulfate deficiency impairs 1-selectin- and chemokine-mediated neutrophil trafficking during inflammatory responses. Nat Immunol. (2005) 6:902-10. doi: $10.1038 /$ ni1233

32. Bao X, Moseman EA, Saito H, Petryniak B, Petryanik B, Thiriot A, et al. Endothelial heparan sulfate controls chemokine presentation in recruitment of lymphocytes and dendritic cells to lymph nodes. Immunity. (2010) 33:817-29. doi: 10.1016/j.immuni.2010.10.018

33. Fukasawa M, Sekine F, Miura M, Nishijima M, Hanada K. Involvement of heparan sulfate proteoglycans in the binding step for phagocytosis of latex beads by chinese hamster ovary cells. Exp Cell Res. (1997) 230:154-62. doi: 10.1006/excr.1996.3403

34. Dehio C, Freissler E, Lanz C, Gómez-Duarte OG, David G, Meyer TF. Ligation of cell surface heparan sulfate proteoglycans by antibody-coated beads stimulates phagocytic uptake into epithelial cells: a model for cellular invasion by neisseria gonorrhoeae. Exp Cell Res. (1998) 242:528-39. doi: 10.1006/excr.1998.4116

35. Gebska MA, Titley I, Paterson HF, Morilla RM, Davies DC, GruszkaWestwood AM, et al. High-affinity binding sites for heparin generated on leukocytes during apoptosis arise from nuclear structures segregated during cell death. Blood. (2002) 99:2221-7. doi: 10.1182/blood.V99.6.2221

36. Clasper S, Vekemans S, Fiore M, Plebanski M, Wordsworth P, David G, et al. Inducible expression of the cell surface heparan sulfate proteoglycan syndecan-2 (fibroglycan) on human activated macrophages can regulate fibroblast growth factor action. J Biol Chem. (1999) 274:24113-23. doi: $10.1074 /$ jbc.274.34.24113

37. Jones KS, Petrow-Sadowski C, Bertolette DC, Huang Y, Ruscetti FW. Heparan sulfate proteoglycans mediate attachment and entry of human t-cell leukemia virus type 1 virions into CD4+ t cells. J Virol. (2005) 79:12692-702. doi: 10.1128/JVI.79.20.12692-12702.2005

38. Sanderson RD, Børset M. Syndecan-1 in b lymphoid malignancies. Ann Hematol. (2002) 81:125-35. doi: 10.1007/s00277-002-0437-8

39. Reine TM, Kusche-Gullberg M, Feta A, Jenssen T, Kolset SO. Heparan sulfate expression is affected by inflammatory stimuli in primary human endothelial cells. Glycoconj J. (2012) 29:67-76. doi: 10.1007/s10719-011-9365-y

40. Berninsone P, Hirschberg CB. Heparan sulfate/heparin n-deacetylase/Nsulfotransferase. The $\mathrm{N}$-sulfotransferase activity domain is at the 
carboxyl half of the holoenzyme. J Biol Chem. (1998) 273:25556-9. doi: 10.1074/jbc.273.40.25556

41. Krenn EC, Wille I, Gesslbauer B, Poteser M, van Kuppevelt TH, Kungl AJ. Glycanogenomics: a CPCR-approach to investigate biological glycan function. Biochem Biophys Res Commun. (2008) 375:297-302. doi: 10.1016/j.bbrc.2008.07.144

42. Carter NM, Ali S, Kirby JA. Endothelial inflammation: the role of differential expression of $\mathrm{n}$-deacetylase/ $\mathrm{N}$-sulphotransferase enzymes in alteration of the immunological properties of heparan sulphate. J Cell Sci. (2003) 116:3591600. doi: $10.1242 /$ jcs. 00662

43. Adhikari N, Rusch M, Mariash A, Li Q, Selleck SB, Hall JL. Alterations in heparan sulfate in the vessel in response to vascular injury in the mouse. $J$ Cardiovasc Transl Res. (2008) 1:236-40. doi: 10.1007/s12265-008-9047-8

44. Rops ALWMM, Loeven MA, van Gemst JJ, Eversen I, Van Wijk XM, Dijkman HB, et al. Modulation of heparan sulfate in the glomerular endothelial glycocalyx decreases leukocyte influx during experimental glomerulonephritis. Kidney Int. (2014) 86:932-42. doi: 10.1038/ki.2014.115

45. Martinez P, Denys A, Delos M, Sikora AS, Carpentier M, Julien S, et al. Macrophage polarization alters the expression and sulfation pattern of glycosaminoglycans. Glycobiology. (2015) 25:502-13. doi: 10.1093/glycob/cwu137

46. Ferreras L, Moles A, Situmorang GR, El Masri R, Wilson IL, Cooke $\mathrm{K}$, et al. Heparan sulfate in chronic kidney diseases: exploring the role of 3-O-sulfation. Biochim Biophys Acta Gen Subj. (2019) 1863:839-48. doi: 10.1016/j.bbagen.2019.02.009

47. Sikora A-S, Delos M, Martinez P, Carpentier M, Allain F, Denys A. Regulation of the expression of heparan sulfate 3-O-Sulfotransferase 3B (HS3ST3B) by inflammatory stimuli in human monocytes. J Cell Biochem. (2016) 117:152942. doi: $10.1002 /$ jcb. 25444

48. Axelsson J, Xu D, Kang BN, Nussbacher JK, Handel TM, Ley K, et al. Inactivation of heparan sulfate 2-O-sulfotransferase accentuates neutrophil infiltration during acute inflammation in mice. Blood. (2012) 120:1742-51. doi: 10.1182/blood-2012-03-417139

49. Parish CR, Freeman C, Hulett MD. Heparanase: a key enzyme involved in cell invasion. Biochim Biophys Acta. (2001) 1471:M99-108. doi: 10.1016/S0304-419X(01)00017-8

50. Vlodavsky I, Gross-Cohen M, Weissmann M, Ilan N, Sanderson RD. Opposing functions of heparanase-1 and heparanase-2 in cancer progression. Trends Biochem Sci. (2018) 43:18-31. doi: 10.1016/j.tibs.2017.10.007

51. Schmidt EP, Yang Y, Janssen WJ, Gandjeva A, Perez MJ, Barthel L, et al. The pulmonary endothelial glycocalyx regulates neutrophil adhesion and lung injury during experimental sepsis. Nat Med. (2012) 18:1217-23. doi: $10.1038 / \mathrm{nm} .2843$

52. Bartlett MR, Underwood PA, Parish CR. Comparative analysis of the ability of leucocytes, endothelial cells and platelets to degrade the subendothelial basement membrane: evidence for cytokine dependence and detection of a novel sulfatase. Immunol Cell Biol. (1995) 73:113-24. doi: $10.1038 /$ icb. 1995.19

53. Digre A, Singh K, Åbrink M, Reijmers RM, Sandler S, Vlodavsky I, Li J-P. Overexpression of heparanase enhances $t$ lymphocyte activities and intensifies the inflammatory response in a model of murine rheumatoid arthritis. Sci Rep. (2017) 7:46229. doi: 10.1038/srep46229

54. Parish CR, Freeman C, Ziolkowski AF, He YQ, Sutcliffe EL, Zafar A, et al. Unexpected new roles for heparanase in type 1 diabetes and immune gene regulation. Matrix Biol J Int Soc Matrix Biol. (2013) 32:228-33. doi: 10.1016/j.matbio.2013.02.007

55. O'Callaghan P, Zhang X, Li J-P. Heparan sulfate proteoglycans as relays of neuroinflammation. J Histochem Cytochem Off J Histochem Soc. (2018) 66:305-19. doi: 10.1369/0022155417742147

56. Buczek-Thomas JA, Nugent MA. Elastase-mediated release of heparan sulfate proteoglycans from pulmonary fibroblast cultures. A mechanism for basic fibroblast growth factor (bFGF) release and attenuation of bfgf binding following elastase-induced injury. J Biol Chem. (1999) 274:25167-72. doi: $10.1074 / j b c .274 .35 .25167$

57. Marshall LJ, Ramdin LSP, Brooks T, DPhil PC, Shute JK. Plasminogen activator inhibitor-1 supports IL-8-mediated neutrophil transendothelial migration by inhibition of the constitutive shedding of endothelial
IL-8/heparan sulfate/syndecan-1 complexes. J Immunol Baltim. (2003) 171:2057-65. doi: 10.4049/jimmunol.171.4.2057

58. Nissinen L, Kähäri V-M. Matrix metalloproteinases in inflammation. Biochim Biophys Acta. (2014) 1840:2571-80. doi: 10.1016/j.bbagen.2014.03.007

59. Ihrcke NS, Platt JL. Shedding of heparan sulfate proteoglycan by stimulated endothelial cells: evidence for proteolysis of cell-surface molecules. J Cell Physiol. (1996) 168:625-37.

60. Hayashida K, Parks WC, Park PW. Syndecan-1 shedding facilitates the resolution of neutrophilic inflammation by removing sequestered CXC chemokines. Blood. (2009) 114:3033-43. doi: 10.1182/blood-2009-02-2 04966

61. Wrenshall LE, Cerra FB, Singh RK, Platt JL. Heparan sulfate initiates signals in murine macrophages leading to divergent biologic outcomes. J Immunol Baltim. (1995) 154:871-80.

62. Wrenshall LE, Platt JL. Regulation of $\mathrm{t}$ cell homeostasis by heparan sulfatebound IL-2. J Immunol Baltim. (1999) 163:3793-800.

63. Goodall KJ, Poon IKH, Phipps S, Hulett MD. Soluble heparan sulfate fragments generated by heparanase trigger the release of proinflammatory cytokines through TLR-4. PLoS ONE. (2014) 9:e109596. doi: 10.1371 /journal.pone. 0109596

64. Platt JL, Wrenshall LE, Johnson GB, Cascalho M. Heparan sulfate proteoglycan metabolism and the fate of grafted tissues. Adv Exp Med Biol. (2015) 865:123-40. doi: 10.1007/978-3-319-18603-0_8

65. Akbarshahi H, Axelsson JBF, Said K, Malmström A, Fischer H, Andersson R. TLR4 dependent heparan sulphate-induced pancreatic inflammatory response is IRF3-mediated. J Transl Med. (2011) 9:219. doi: 10.1186/1479-5876-9-219

66. Kodaira Y, Nair SK, Wrenshall LE, Gilboa E, Platt JL. Phenotypic and functional maturation of dendritic cells mediated by heparan sulfate. $J$ Immunol Baltim. (2000) 165:1599-604. doi: 10.4049/jimmunol.165.3.1599

67. Johnson GB, Brunn GJ, Platt JL. Cutting edge: an endogenous pathway to systemic inflammatory response syndrome (SIRS)-like reactions through toll-like receptor 4. J Immunol Baltim. (2004) 172:20-4. doi: 10.4049/jimmunol.172.1.20

68. Dhoot GK, Gustafsson MK, Ai X, Sun W, Standiford DM, Emerson CP Jr. Regulation of Wnt signaling and embryo patterning by an extracellular sulfatase. Science. (2001) 293:1663-6. doi: 10.1126/science.293.553 5.1663

69. Morimoto-Tomita M, Uchimura K, Werb Z, Hemmerich S, Rosen SD. Cloning and characterization of two extracellular heparin-degrading endosulfatases in mice and humans. J Biol Chem. (2002) 277:49175-85. doi: 10.1074/jbc.M205131200

70. Ai X, Do AT, Kusche-Gullberg M, Lindahl U, Lu K, Emerson CP Jr. Substrate specificity and domain functions of extracellular heparan sulfate 6-O-endosulfatases, QSulf1 and QSulf2. J Biol Chem. (2006) 281:4969-76. doi: 10.1074/jbc.M511902200

71. Frese MA, Milz F, Dick M, Lamanna WC, Dierks T. Characterization of the human sulfatase sulf1 and its high affinity heparin/heparan sulfate interaction domain. J Biol Chem. (2009) 284:28033-44. doi: 10.1074/jbc.M109.035808

72. Tang R, Rosen SD. Functional consequences of the subdomain organization of the sulfs. J Biol Chem. (2009) 284:21505-14. doi: 10.1074/jbc.M109.0 28472

73. Seffouh A, El Masri R, Makshakova O, Gout E, Hassoun ZEO, Andrieu J$\mathrm{P}$, et al. Expression and purification of recombinant extracellular sulfatase HSulf-2 allows deciphering of enzyme sub-domain coordinated role for the binding and 6-O-desulfation of heparan sulfate. Cell Mol Life Sci CMLS. (2019) 76:1807-19. doi: 10.1007/s00018-019-03027-2

74. El Masri R, Seffouh A, Lortat-Jacob H, Vivès RR. The "in and out" of glucosamine 6-O-sulfation: the 6th sense of heparan sulfate. Glycoconj J. (2017) 34:285-98. doi: 10.1007/s10719-016-9736-5

75. Rosen SD, Lemjabbar-Alaoui H. Sulf-2: an extracellular modulator of cell signaling and a cancer target candidate. Expert Opin Ther Targets. (2010) 14:935-49. doi: 10.1517/14728222.2010.504718

76. Vives RR, Seffouh A, Lortat-Jacob H. Post-Synthetic regulation of HS structure: the yin and yang of the sulfs in cancer. Front Oncol. (2014) 3:331. doi: $10.3389 /$ fonc. 2013.00331 
77. Nishitsuji K. Heparan sulfate s-domains and extracellular sulfatases (Sulfs): their possible roles in protein aggregation diseases. Glycoconj J. (2018) 35:387-96. doi: 10.1007/s10719-018-9833-8

78. Sadir R, Baleux F, Grosdidier A, Imberty A, Lortat-Jacob H. Characterization of the stromal cell-derived factor-1alpha-heparin complex. J Biol Chem. (2001) 276:8288-96. doi: 10.1074/jbc.M008110200

79. Uchimura K, Morimoto-Tomita M, Bistrup A, Li J, Lyon M, Gallagher J, et al. HSulf-2, an extracellular endoglucosamine-6-sulfatase, selectively mobilizes heparin-bound growth factors and chemokines: effects on VEGF, FGF-1, and SDF-1. BMC Biochem. (2006) 7:2. doi: 10.1186/1471-2091-7-2

80. Zhang S, Condac E, Qiu H, Jiang J, Gutierrez-Sanchez G, Bergmann C, et al. Heparin-induced leukocytosis requires 6-O-sulfation and is caused by blockade of selectin- and CXCL12 protein-mediated leukocyte trafficking in mice. J Biol Chem. (2012) 287:5542-53. doi: 10.1074/jbc.M111.314716

81. Spillmann D, Witt D, Lindahl U. Defining the interleukin-8-binding domain of heparan sulfate. J Biol Chem. (1998) 273:15487-93. doi: 10.1074/jbc.273.25.15487

82. Pichert A, Schlorke D, Franz S, Arnhold J. Functional aspects of the interaction between interleukin-8 and sulfated glycosaminoglycans. Biomatter. (2012) 2:142-8. doi: 10.4161/biom.21316

83. Stringer SE, Gallagher JT. Specific binding of the chemokine platelet factor 4 to heparan sulfate. J Biol Chem. (1997) 272:20508-14. doi: 10.1074/jbc.272.33.20508

84. Pempe EH, Burch TC, Law CJ, Liu J. Substrate specificity of 6-O-endosulfatase (Sulf-2) and its implications in synthesizing anticoagulant heparan sulfate. Glycobiology. (2012) 22:1353-62. doi: $10.1093 /$ glycob/cws092

85. Shaw JP, Johnson Z, Borlat F, Zwahlen C, Kungl A, Roulin K, et al. The X-Ray structure of RANTES; heparin-derived disaccharides allows the rational design of chemokine inhibitors. Struct Camb. (2004) 12:2081-93. doi: 10.1016/j.str.2004.08.014

86. Sheng GJ, Oh YI, Chang S-K, Hsieh-Wilson LC. Tunable heparan sulfate mimetics for modulating chemokine activity. J Am Chem Soc. (2013) 135:10898-901. doi: 10.1021/ja4027727

87. Jayson GC, Hansen SU, Miller GJ, Cole CL, Rushton G, Avizienyte E, et al. Synthetic heparan sulfate dodecasaccharides reveal single sulfation site interconverts CXCL8 and CXCL12 chemokine biology. Chem Commun Camb Engl. (2015) 51:13846-9. doi: 10.1039/C5CC05222J

88. Seffouh A, Milz F, Przybylski C, Laguri C, Oosterhof A, Bourcier S, et al. HSulf sulfatases catalyze processive and oriented 6-O-desulfation of heparan sulfate that differentially regulates fibroblast growth factor activity. Faseb J. (2013) 27:2431-9. doi: 10.1096/fj.12-226373

89. Rops AL, van den Hoven MJ, Baselmans MM, Lensen JF, Wijnhoven TJ, van den Heuvel LP, et al. Heparan sulfate domains on cultured activated glomerular endothelial cells mediate leukocyte trafficking. Kidney Int. (2008) 73:52-62. doi: 10.1038/sj.ki.5002573

90. Wang L, Brown JR, Varki A, Esko JD. Heparin's anti-inflammatory effects require glucosamine 6-O-sulfation and are mediated by blockade of 1 - and p-selectins. J Clin Invest. (2002) 110:127-36. doi: 10.1172/JCI0214996

91. Uchimido R, Schmidt EP, Shapiro NI. The glycocalyx: a novel diagnostic and therapeutic target in sepsis. Crit Care. (2019) 23:6. doi: 10.1186/s13054-018-2292-6

92. Oshima K, Han X, Ouyang Y, El Masri R, Yang Y, Haeger SM, et al. Loss of endothelial sulfatase-1 after experimental sepsis attenuates subsequent pulmonary inflammatory responses. Am J Physiol Lung Cell Mol Physiol. (2019) 317:L667-L77. doi: 10.1152/ajplung.00175.2019

93. Celie JW, Rutjes NW, Keuning ED, Soininen R, Heljasvaara R, Pihlajaniemi T, et al. Subendothelial heparan sulfate proteoglycans become major 1-selectin and monocyte chemoattractant protein-1 ligands upon renal ischemia/reperfusion. Am J Pathol. (2007) 170:1865-78. doi: 10.2353/ajpath.2007.070061

94. Sikora A-S, Hellec C, Carpentier M, Martinez P, Delos M, Denys A, et al. Tumour-necrosis factor- $\alpha$ induces heparan sulfate 6-O-endosulfatase 1 (Sulf-1) expression in fibroblasts. Int J Biochem Cell Biol. (2016) 80:57-65. doi: 10.1016/j.biocel.2016.09.021

95. Alhasan AA, Spielhofer J, Kusche-Gullberg M, Kirby JA, Ali S. Role of 6O-sulfated heparan sulfate in chronic renal fibrosis. J Biol Chem. (2014) 289:20295-306. doi: 10.1074/jbc.M114.554691

96. Yue X, Li X, Nguyen HT, Chin DR, Sullivan DE, Lasky JA. Transforming growth factor-betal induces heparan sulfate 6-O-endosulfatase 1 expression in vitro and in vivo. J Biol Chem. (2008) 283:20397-407. doi: 10.1074/jbc.M802850200

97. Yue X, Lu J, Auduong L, Sides MD, Lasky JA. Overexpression of sulf2 in idiopathic pulmonary fibrosis. Glycobiology. (2013) 23:709-19. doi: $10.1093 /$ glycob/cwt010

98. Yue X. Epithelial deletion of sulf2 exacerbates bleomycin-Induced lung injury, inflammation, and mortality. Am J Respir Cell Mol Biol. (2017) 57:560-9. doi: 10.1165/rcmb.2016-0367OC

99. Chen G, Nakamura I, Dhanasekaran R, Iguchi E, Tolosa EJ, Romecin PA, et al. Transcriptional induction of periostin by a sulfatase 2-TGF $\beta 1$-SMAD signaling axis mediates tumor angiogenesis in hepatocellular carcinoma. Cancer Res. (2017) 77:632-45. doi: 10.1158/0008-5472.CAN-15-2556

100. Holst CR, Bou-Reslan H, Gore BB, Wong K, Grant D, Chalasani $S$, et al. Secreted sulfatases sulf1 and sulf2 have overlapping yet essential roles in mouse neonatal survival. PLOS ONE. (2007) 2:e575. doi: 10.1371/journal.pone.0000575

101. Lum DH, Tan J, Rosen SD, Werb Z. Gene trap disruption of the mouse heparan sulfate 6-O-endosulfatase gene, sulf2. Mol Cell Biol. (2007) 27:67888. doi: 10.1128/MCB.01279-06

102. Sahota AP, Dhoot GK. A novel SULF1 splice variant inhibits wnt signalling but enhances angiogenesis by opposing SULF1 activity. Exp Cell Res. (2009) 315:2752-64. doi: 10.1016/j.yexcr.2009.06.029

103. Gill RB, Day A, Barstow A, Liu H, Zaman G, Dhoot GK. Sulf2 gene is alternatively spliced in mammalian developing and tumor tissues with functional implications. Biochem Biophys Res Commun. (2011) 414:468-73. doi: 10.1016/j.bbrc.2011.09.088

104. Gill RBS, Day A, Barstow A, Zaman G, Chenu C, Dhoot GK. Mammalian sulf1 RNA alternative splicing and its significance to tumor growth regulation. Tumour Biol J Int Soc Oncodev Biol Med. (2012) 33:1669-1680. doi: 10.1007/s13277-012-0423-2

105. Gill RM, Michael A, Westley L, Kocher HM, Murphy JI, Dhoot GK. SULF1/SULF2 splice variants differentially regulate pancreatic tumor growth progression. Exp Cell Res. (2014) 324:157-71. doi: 10.1016/j.yexcr.2014.04.001

Conflict of Interest: The authors declare that the research was conducted in the absence of any commercial or financial relationships that could be construed as a potential conflict of interest.

Copyright (C) 2020 El Masri, Crétinon, Gout and Vivès. This is an open-access article distributed under the terms of the Creative Commons Attribution License (CC BY). The use, distribution or reproduction in other forums is permitted, provided the original author(s) and the copyright owner(s) are credited and that the original publication in this journal is cited, in accordance with accepted academic practice. No use, distribution or reproduction is permitted which does not comply with these terms. 